\title{
Louisa's Birth
}

\author{
Rachel Mann
}

\begin{abstract}
In this column, Rachel Mann shares the story of the birth of her third daughter, Louisa. After a previous pregnancy loss, Mann chose to give birth to her third baby in a hospital with attending care from an obstetrician. In spite of the high-risk medical environment, she was able to have an unmedicated, powerful birth. Mann's careful planning, the support of her husband and doula, and her confidence in her ability to give birth helped make Louisa's birth all that Mann hoped it would be.
\end{abstract}

The Journal of Perinatal Education, 20(4), 182-184, doi: 10.1891/1058-1243.20.4.182

Keywords: birth, unmedicated birth, birth plan, labor support, normal birth, pregnancy loss

Do you have a birth story that illustrates the power of childbirth and encourages women to give birth with confidence? We invite you to submit your story for possible publication in The Journal of Perinatal Education (JPE). Please send your story or query to Judith Lothian, Associate Editor (Jalothian@aol.com).

V

The JPE 20(3) 2011 Summer issue featured Allison Walsh's birth story describing the home waterbirth of her third child, Nora, from the perspective of Allison, her husband Paul, and their two other children, Jane and Gavin. The Walsh family's article, titled "Welcoming Nora: A Family Event," is available online at JPE'S IngentaConnect site (http:// www.ingentaconnect.com/ content/springer/jpe).
In the final weeks of my pregnancy with Louisa, my third daughter, I became nervous about the birth. My anxiety had everything to do with my birth history. My first daughter, Bella, was born in 2003 at a community hospital on Long Island, New York, with an obstetrician and a doula. Although Bella's birth was straightforward, it was frustrating having to try to convince the medical personnel (unsuccessfully) that I wanted an unmedicated birth. I was also unhappy that Bella was taken away from me an hour after she was born.

When I became pregnant again a year later, I sought out midwifery care, having heard about the gentle touch of midwives. My second daughter, Ruby, had a very happy birth with my dear friend, Allison Walsh, as my doula and with a wonderful experienced midwife, Barbara Sellars, at the birthing center at St. Luke's Roosevelt Hospital in Manhattan. It was so empowering to give birth quietly, surrounded by lovely women and my supportive husband Josh, all of whom believed that I could do it. I loved that Ruby was never separated from us, that we all had the chance to recover on a big family-sized bed after the birth, and that after giving birth at 11:11 a.m., we were all home that night for dinner.

When Bella and Ruby were 5 and 3 years old, respectively, we moved to London, England, because of Josh's job transfer. When I became pregnant several months later, I registered for prenatal care and to give birth at a private hospital with a midwife-run birthing unit not far from where we lived. I had heard many good things about the place and its staff. But the pregnancy did not go well. After a month of unexplained bleeding, my water broke at 22 weeks and 4 days of gestation. The midwife on call told me I had to go to a public hospital because the private hospital and birthing unit where I had registered were not equipped to treat complications or early births. I was admitted to the Royal Free Hospital in Hampstead and, after 4 harrowing days, I gave birth to a stillborn girl weighing $1 \mathrm{lb}, 8 \mathrm{oz}$. It was the most difficult experience of my life, and one that still haunts me and my family. The reality of losing our baby was bad enough, but it was made worse by the fact that I had no medical caregiver or team who watched over me in the hospital. I had to tell my story of why I was there over 
and over, each time, to the separate cadre of doctors and nurses who arrived for their 12-hour shifts.

A year later, we moved back to New York. When I learned I was pregnant again, I was terrified. I just could not bear the idea of going through a perinatal loss again, and not knowing what had caused our previous loss added to my fear. I am fortunate to have a father who is an experienced obstetriciangynecologist and who has always been there for me as a source of information and guidance. He recommended that I seek out high-risk obstetrical care, in an effort to do everything I possibly could to bring my pregnancy to term and give birth to a healthy baby. This was not an easy decision for me because I knew it meant that I would not give birth in a birthing center, or with midwives. But whenever I felt regret about that, I remembered my experience at the Royal Free Hospital, and it helped me feel secure in my decision. I needed to know that my medical team could care for me no matter what happened. With my father's assistance, I found a doctor at the faculty practice in Maternal-Fetal Medicine at the New York-Presbyterian/Weill Cornell Medical Center where I saw the same obstetrician at every appointment. Dr. Zervoudakis was familiar with my case and took several precautions throughout my pregnancy to help me reach term, including prescribing 17-P injections (17 alpha-hydroxyprogesterone), giving me antibiotics for a persistent infection, and directing me to visit a hematologist who prescribed daily aspirin.

As the birth approached, I was nervous because although I had only met one obstetrician in the practice, there were five in the group and, therefore, the chances were high that I would not know the doctor on call. In addition, I wondered if it was possible to have a gentle, unmedicated birth-as I had with Ruby - in a highly medicalized setting. It was ironic that although my pregnancy was considered high-risk because of my history, there was no reason for my birth to be placed in that category. I had given birth vaginally before, and I knew that I was capable of doing so again. But still, I was afraid, perhaps simply of the unknown.

One thing that reassured me was that I would have my friend Allison as my doula, again. She had been at Ruby's birth and had been a great source of support to me after my pregnancy loss. She knew how I wanted the birth to be, and I felt sure that she would do everything she could to help me. She helped me to write a birth plan, something I had never done before. The birth plan allowed me to put in writing all the concerns I had about what might happen in a hospital birth.

I was due to give birth on a Monday, and that final weekend of the pregnancy was a very busy one. Saturday night was Purim, a Jewish holiday when the community dresses up in costumes and celebrates. My daughter Bella, now 8 years old, was in a play that night in our synagogue, and we were all out late. The next morning, we attended my nephew's bar mitzvah. When I woke to use the bathroom around 5:00 a.m., I wondered if I might be leaking water. But it was nothing much, and I was not having contractions; so I put on my dress and heels and fixed my daughters' hair. Off we went to New Jersey for the party. Throughout the morning, I felt "off"crampy, a bit nauseated, and tired-but also happy. I really enjoyed the bar mitzvah party and danced the hora with my family (a sight to behold, being 9 months pregnant!). Toward the end of the party, I became more certain that my water might be leaking, so we made arrangements to leave Bella and Ruby with my parents, and Josh and I decided to go. Just after we left the synagogue, as we were walking uphill to the car, I felt a gush. Good timing!

We called the doctor on call, and she said that because I was multiparous and Group B strep positive, I should come in to the hospital, but not to rush ("no need for an ambulance"). I called Allison, who told me we should go home, change clothes, and get my hospital bag. Josh especially was glad she said that, because otherwise he would have spent the next many hours in a suit. Allison also said that because it did not sound like I was in active labor yet (I was laughing on the phone), she would finish her family barbecue and head to the hospital to meet me later in the day. I agreed that that was fine.

We arrived at the hospital around 4:00 p.m., with my contractions still more than 5 minutes apart and not so strong that I could not talk through them. The doctor with whom I had spoken on the phone, Dr. Lee, had made arrangements for me to have a direct admission, so it was not long before we were in a room, and I was getting my intravenous antibiotics for Group B strep. Although it was clearly a medical environment, the birthing room was large and comfortable, with plenty of room to move around.

I wondered if it was possible to have a gentle, unmedicated birth—as I had with Ruby—in a highly medicalized setting. 
My first nurse put me at ease-when I told her that I did not want

pain medication, she said she had given birth that way, too.

My first nurse put me at ease-when I told her that I did not want pain medication, she said she had given birth that way, too. A nurse in a hospital who was not pushing pain medications! Was this possible? She offered and brought me a birth ball to sit on.

Dr. Lee came in and examined me. I liked her immediately. Without my having to say much, she seemed to understand where I was coming fromthat I wanted to have an intervention-free birth. I was still only $3 \mathrm{~cm}$ dilated, and although my contractions were getting more frequent, I was still too comfortable- this was not the real thing, yet. Dr. Lee told me I could walk around and get labor going.

For the next many hours, I walked around the labor and delivery floor and sat on the birth ball. Allison arrived in the early evening and encouraged me to eat and drink. I had already been snacking on almonds and a granola bar and was sipping on a fruit drink. Sometime late in the night, my labor finally advanced and started to get difficult. I began to vocalize, chanting "om" through each contraction, which was how I labored with Bella and Ruby. I felt self-conscious at first, but gradually settled into the place where I had to do it - the chanting made each contraction manageable.

As I was laboring, I had in the back of my mind the stories of several of my friends whose babies had been born really quickly_-an hour or two from start to finish. I kept thinking, "This is my fourth labor; surely the baby must be coming soon?" The harder it got, the more I hoped that I was getting toward the end.

At 2:00 a.m., Dr. Lee checked me again and I learned that I was still only $3-4 \mathrm{~cm}$ dilated. I was devastated. All those hours, and all that work, and I was hardly progressing at all. She told me that the clock was ticking (I had told them that my water broke at 2:00 p.m., which was when I had the gush as I was leaving the bar mitzvah) and that if labor exceeded 18 hours with ruptured membranes, the pediatricians would likely take the baby away for tests after the birth. Also, I knew that Dr. Lee was only on call until 8:00 a.m., and I did not want to have to switch to another unknown doctor at

In the end, the birth plan that I wrote never left my bag. But writing it helped me clarify in my own mind what I wanted and how to speak up for myself. I believe that this thinking ahead allowed me to have a powerful birth in a medical setting. this point. Exhausted, discouraged, and eager to meet my baby, I agreed to have Pitocin to speed things along.

The Pitocin drip began around 2:30 a.m., and it made the contractions excruciating. Allison and Josh helped me to try different positions in the bed, moving from side to side and on my knees. I began throwing up, which I did in all my labors toward the end. There were times when the chanting felt inadequate, when I felt the pain completely overwhelm me, and I struggled to maintain focus during the contractions. I do not remember ever feeling that level of pain during Ruby's birth. I think this is the difference the Pitocin made. I could not imagine going on much longer in this way. I asked Dr. Lee to check me again; I told everyone that if I still had not progressed, it was time for an epidural. But when Dr. Lee told me I was $6 \mathrm{~cm}$ going on 7, I knew I was almost there, and that I could do it.

Minutes later, while leaning on my knees against the back of the bed, I felt the urge to push. The nurse told me I had to get down and turn over. Dr. Lee checked me again and said I still was not fully dilated, so I waited through a few contractions, and then I got back up on my knees, which was really working to bring the baby down. Finally, it was time. I turned over, sitting up, ready to give birth. Dr. Lee asked if she could collapse the end of the bed, and I said no. I had my eyes shut as I was pushing, but later, Allison told me that the doctor looked a bit panicked assisting the birth of a baby, in a way that she was not accustomed to, on the bed. But I have to give Dr. Lee credit for compromising to let me determine how I should give birth.

In the end, the birth plan that I wrote never left my bag. But writing it helped me clarify in my own mind what I wanted and how to speak up for myself. I believe that this thinking ahead allowed me to have a powerful birth in a medical setting.

After a few pushes, Louisa Ruth was born at 4:54 a.m. on March 21, 2011, her due date. She weighed $7 \mathrm{lbs}, 10 \mathrm{oz}$. I was so relieved to be done with labor and to finally hold my healthy baby-another girl! Feeling immense joy, Josh and I swooned over our beautiful daughter. Later that day, Bella and Ruby came to the hospital to meet their baby sister. They were thrilled and relieved, because they also had anxiety throughout my pregnancy. It was such a miracle to finally have Louisa Ruth with us.

RACHEL MANN is a freelance writer who lives with her husband and three daughters in New York City, New York. 